\title{
新しい境界追跡型レベルセットトポロジー最適化法の構築*
}

\author{
山㟝 慎太郎 ${ }^{* 1}, \quad 川$ 川本 敦史 ${ }^{* 2}, \quad$ 野村 壮史 ${ }^{* 2, * 3}$ ，藤田 喜久雄 $* 4$
}

\section{Construction of a New Boundary Tracking Type Level-set Topology Optimization Method}

\author{
Shintaro YAMASAKI*1 ${ }^{*}$ Atsushi KAWAMOTO, Tsuyoshi NOMURA and Kikuo FUJITA \\ ${ }^{* 1}$ Department of Mechanical Engineering, Osaka University, 2-1 Yamadaoka, Suita, Osaka 565-0871, Japan
}

This paper proposes a new level-set based topology optimization method incorporating a boundary tracking mesh generation method and non-linear programming. Since the mesh generation method provides a mesh conforming to the structural boundary at every optimization iteration, grayscale elements are completely eliminated during optimization. On the other hand, non-linear programming is widely used for efficiently updating the design variables in conventional topology optimization techniques such as homogenization and density based topology optimization. By incorporating these methods, we configure a new topology optimization method for virtually realizing completely grayscale-free, efficient topology optimization. In this paper, we first develop the mathematical formulation for obtaining sensitivity information on level-set based topology optimization problems and then implement a boundary tracking type levelset topology optimization method with the sequential linear programming (SLP) for designing compliant mechanisms. Further, we apply it to a numerical example for confirming the advantages of the proposed method and framework. Even with SLP, which is a most simple scheme of non-linear programming, the result demonstrate the relevance and promise of the proposed framework as a new class of grayscale-free topology optimization.

Key Words : structural design, optimum design, engineering optimization

\section{1. 緒言}

数学的, 物理学的根拠に基づき優れた性能をもつ構造物を設計する手法である構造最適化法は, 大きく寸法最適 化法, 形状最適化法, トポロジー最適化法 ${ }^{(1)(2)}$ に分類される. これらの中で, トポロジー最適化法 ${ }^{(1)(2)}$ は, 形状 と形態を同時に考慮した設計解を得られる, 最も自由度の高い構造最適化法である. 特に, レベルセット法 ${ }^{(3)} の$ もつ有用な性質を利用したトポロジー最適化法, すなわちレベルセット法に基づくトポロジー最適化法 ${ }^{(4)}{ }^{(5)}$ は, 今日大きな注目を集めている。

レベルセット法は, レベルセット関数と呼ばれるスカラー関数の符号によって二相の形状と形態を表現する, 才 イラー座標系に基づく形状表現法である，すなわち，ある点のレベルセット関数值の符号が正であれば，その点は 第一相に属するとみなし, 逆に符号が負であれば, その点は第二相に属するとみなす．そして，レベルセット関数 のゼロ等值面，すなわちレベルセット境界を二相の境界とみなす．レベルセット法を用いれば二相の境界が明確 に表現されるので, レベルセット法に基づくトポロジー最適化では, 最適化対象の構造物の形状境界を常に明確 にしながら構造最適化を行えるようになる. また, 様々な形態変更がレベルセット関数の更新により実現される.

レベルセット法に基づくトポロジー最適化法のプログラムを実装する場合, 設計領域はオイラーメッシュによっ て分割され，レベルセット関数はオイラーメッシュの各節点において保持される. 通常、レベルセット境界はオ

*1 正員, 大阪大学大学院工学研究科機械工学専攻（广 565-0871 大阪府吹田市山田丘 2-1）

$* 2$ 正員, 株式会社豊田中央研究所

*3 正員, Toyota Research Institute of North America

*4 フェロー, 大阪大学大学院工学研究科機械工学専攻

Email: yamasaki@mech.eng.osaka-u.ac.jp

[No.13-22] 日本機械学会 第 23 回設計工学・システム部門講演会講演論文集 [2013.10.23-25, 沖縄県読谷村] 
イラーメッシュの形状と一致しないため, 状態変数, ひいては目的関数を計算するために何らかの数值計算手法 が必要となる. このため, レベルセット境界周辺において, 材料物性值を構造材料の值から空気の值へ滑らかに 変化するよう分布させる方法がよく用いられる．この方法では, レベルセット境界周辺にいわゆるグレースケー ル要素が生成されるため, オイラーメッシュを用いて状態変数と目的関数を計算できるものの, 得られた設計解 の工学的な観点からの解釈が難しくなるという問題がある.

この問題を解決するため, 著者らは文献 ${ }^{(6)} に$ に拀いて, 境界追跡型レベルセットトポロジ一最適化法を提案した. この方法では, レベルセット関数を保持するためにオイラーメッシュを用い, 状態変数と目的関数を計算するため に，オイラーメッシュの各節点を移動させることにより生成されるレベルセット境界追跡メッシュを用いる．レ ベルセット境界追跡メッシュはレベルセット境界を常に正確に追跡するため，この方法では，レベルセット境界 周辺にグレースケール要素は生成されない，現在までに，金属導波管設計問題 ${ }^{(6)}$ およびコンプライアントメカニ ズム設計問題 ${ }^{(7)}$ を対象とした境界追跡型レベルセットトポロジー最適化法が提案されている.

これらの研究 ${ }^{(6)(7)}$ では, 従来のレベルセット法に基づくトポロジー最適化の枠組みに従い, レベルセット方程 式 ${ }^{(8)}$ を解くことによりレベルセット関数を更新していた，一方で，均質化法や密度法に基づく，いわゆる標準的 なトポロジー最適化法 ${ }^{(1)(2)}$ では, 一般的に, 非線形計画法を用いて設計変数を更新する. 構造最適設計問題にお いて, 多くの場合, 目的関数や制約関数は非線形であるため, 設計変数の更新に非線形計画法を用いるのは自然 なアプローチである. また, 非線形計画法分野の最新の研究成果を活用することによって, 構造最適化の高効率 化や, 従来解くことの出来なかった複雑な構造最適化問題の求解が期待できる.

そこで筆者らは，非線形計画法を用いて設計変数を更新する枠組みと，境界追跡型レベルセットトポロジー最 適化法を組み合わせることを提案する．前述のように，境界追跡型レベルセットトポロジー最適化法はグレース ケールフリーのトポロジー最適化法であるため, この組み合わせにより, 標準的な設計変数更新の枠組みをもつ, グレースケールフリーのトポロジー最適化法が実現される. 本研究では, 提案法の最初のプロトタイプとして, コ ンプライアントメカニズム設計問題を対象とした最適化法を, 逐次線形計画法 (SLP) を用いて実装し, 提案法の 妥当性について数值例を用いて検証する.

以下, 第 2 章ではレベルセット法を用いてコンプライアントメカニズム設計問題を定式化し, 第 3 章では提案 法の実装の詳細を説明する. 第 4 章では数值例を用いて提案法の妥当性を検証する. 最後に, 第 5 章に結論を述 べる.

\section{2. 定 式 化}

\section{$2 \cdot 1$ レベルセット法に基づく形状表現}

本節では, レベルセット法に基づく形状表現について説明する。一種類の構造材料と空気から構成される設計 領域 $D$ について, 構造材料で満たされる物体領域を $\Omega$, 空気で満たされる空洞領域を $D \backslash \Omega$ と表すと, $D$ におけ る任意の $\Omega$ の形状と形態は，レベルセット関数 $\phi$ を用いて以下のように表される.

$$
\begin{array}{lll}
\phi(\mathbf{x})>0 & \text { for } & \forall \mathbf{x} \in \Omega \backslash(\partial \Omega \backslash \partial D) \\
\phi(\mathbf{x})=0 & \text { for } & \forall \mathbf{x} \in \partial \Omega \backslash \partial D \\
\phi(\mathbf{x})<0 & \text { for } & \forall \mathbf{x} \in D \backslash \Omega
\end{array}
$$

ここで, $\mathbf{x}$ は $D$ 内の点の座標であり, $\partial D$ と $\partial \Omega$ は, それぞれ $D$ と $\Omega$ の境界である.

$\Omega$ によって表現される構造が, レベルセット法に基づくトポロジー最適化における最適化対象構造物であり, 対 象構造物の外形はレベルセット境界によって表される.

\section{$2 \cdot 2$ コンプライアントメカニズム設計問題}

本節では, レベルセット法を用いてコンプライアントメカニズム設計問題を定式化する. 最初に, 入力ポート $\partial D_{1}$ と出力ポート $\partial D_{2}$ を一つずつ持つ設計領域 $D$ を考える. 2.1 節で説明したように, 設計領域 $D$ は物体領域 $\Omega$ と空洞領域 $D \backslash \Omega$ から構成される. 構造材料は適切な剛性を持つので, 構造物は $\partial D_{1}$ における入力荷重により変 形する. ここで，目的は， $\partial D_{2}$ におけるある指定された方向への変形を, 三つの制約条件下で最大化することで ある. 一つ目の制約条件は体積制約であり，二つ目の制約条件は入力荷重による極端な変形を防ぐためのコンプ 
ライアンス制約である. 三つ目の制約条件は出力ポートに設置されたワークピースに十分な力を伝えるためのコ ンプライアンス制約である. このとき，設計問題は以下のように定式化される.

$$
\begin{aligned}
\text { minimize } f_{0}(\phi) & :=-\int_{\partial D_{2}} \mathbf{t}_{2} \cdot \mathbf{u}_{1} \mathrm{~d} s \\
\text { subject to } f_{1}(\phi) & :=\int_{D} H(\phi(\mathbf{x})) \mathrm{d} v \leq f_{1 \max } \\
f_{2}(\phi) & :=\int_{\partial D_{1}} \mathbf{t}_{1} \cdot \mathbf{u}_{1} \mathrm{~d} s \leq f_{2 \max } \\
f_{3}(\phi) & :=\int_{\partial D_{2}} \mathbf{t}_{2} \cdot \mathbf{u}_{2} \mathrm{~d} s \leq f_{3 \max }
\end{aligned}
$$

ここで, $\mathbf{t}_{1}$ は入力荷重, $\mathbf{t}_{2}$ は出力ポートにおける望ましい変形方向を指定するためのダミー出力荷重である. $f_{1 \max }$, $f_{2 \max }, f_{3 \max }$ は, それぞれ, $f_{1}(\phi), f_{2}(\phi), f_{3}(\phi)$ の上限值である. $H(\phi(\mathbf{x}))$ は以下で定義されるへビサイド関数で ある.

$$
H(\phi(\mathbf{x}))= \begin{cases}0 & \text { if } \phi(\mathbf{x})<0 \\ 1 & \text { otherwise }\end{cases}
$$

$\mathbf{u}_{1}$ は $\mathbf{t}_{\text {in }}$ が $\partial D_{\text {in }}$ に作用したときの変位場であり, 以下の式より求められる.

$$
\int_{\partial D_{1}} \mathbf{t}_{1} \cdot \hat{\mathbf{u}}_{1} \mathrm{~d} s=\int_{D} \varepsilon\left(\hat{\mathbf{u}}_{1}\right): \mathbf{D}: \varepsilon\left(\mathbf{u}_{1}\right) H(\phi(\mathbf{x})) \mathrm{d} v
$$

ここで, $\hat{\mathbf{u}}_{1}$ は $\mathbf{u}_{1}$ の試行関数， $\varepsilon$ は線形ひずみテンソル， $\mathbf{D}$ は等方性弾性テンソルである. $\mathbf{u}_{2}$ は $\mathbf{t}_{2}$ が $\partial D_{2}$ に作用 したときの変位場であり, 以下の式より求められる.

$$
\int_{\partial D_{2}} \mathbf{t}_{2} \cdot \hat{\mathbf{u}}_{2} \mathrm{~d} s=\int_{D} \varepsilon\left(\hat{\mathbf{u}}_{2}\right): \mathbf{D}: \varepsilon\left(\mathbf{u}_{2}\right) H(\phi(\mathbf{x})) \mathrm{d} v
$$

ここで, $\hat{\mathbf{u}}_{2}$ は $\mathbf{u}_{2}$ の試行関数である.

\section{3. 最適化法の実装}

\section{$3 \cdot 1$ 境界追跡メッシュを用いた状態変数計算}

本研究では, 以前に提案した境界追跡型レベルセットトポロジー最適化法 ${ }^{(7)}$ をいて, 状態変数 $\mathbf{u}_{1}$ と $\mathbf{u}_{2}$ を計算 する. すなわち, オイラーメッシュの各節点においてレベルセット関数を保持し, 最適化の各イタレーション毎 にレベルセット境界を正確に追跡する境界追跡メッシュを生成し，これを用いて状態変数を計算する.

式 (4) と (5) は，境界追跡メッシュを用いて以下の様に離散化される.

$$
\begin{aligned}
\hat{\mathbf{U}}_{1}^{\top}\left\{\mathbf{T}_{1}-\mathbf{K} \mathbf{U}_{1}\right\} & =0 \\
\hat{\mathbf{U}}_{2}^{\top}\left\{\mathbf{T}_{2}-\mathbf{K} \mathbf{U}_{2}\right\} & =0
\end{aligned}
$$

ここで， $\mathbf{T}_{1}$ と $\mathbf{T}_{2}$ は，それぞれ $\mathbf{t}_{1}$ と $\mathbf{t}_{2}$ を離散化した荷重べクトル， $\mathbf{U}_{1}$ と $\mathbf{U}_{2}$ は，それぞれ $\mathbf{u}_{1}$ と $\mathbf{u}_{2}$ の節点べクト ル， $\hat{\mathbf{U}}_{1}$ と $\hat{\mathbf{U}}_{2}$ は，それぞれ $\hat{\mathbf{u}}_{1}$ と $\hat{\mathbf{u}}_{2}$ を離散化した節点べクトルである. $\mathbf{K}$ は以下の式で与えられる全体剛性行列 である.

$$
\mathbf{K}=\bigcup_{e=1}^{n_{\Omega}} \int_{V} \mathbf{B}^{\top} \mathbf{D}^{\mathrm{H}} \mathbf{B} \mathrm{d} v+\bigcup_{e=1}^{n_{D} \backslash \Omega} \int_{V \mathbf{e}} \mathbf{B}^{\top} \boldsymbol{K} \mathbf{D}^{\mathrm{H}} \mathbf{B} \mathrm{d} v
$$

ここで, $\int_{V \mathrm{e}} \mathrm{d} v$ は一要素における体積積分であり， B は一要素内の節点变位とひずみの関係を表す行列である． $\mathbf{D}^{\mathrm{H}}$ は行列形式で表された弾性定数テンソルであり， $\kappa$ は $\mathbf{K}$ が特異となることを防ぐための微小值である. $\bigcup_{e=1}^{n_{\Omega}}$ と $\bigcup_{e=1}^{n_{D \backslash \Omega}}$ は，それぞれ $\Omega$ と $D \backslash \Omega$ に属する要素の和集合を表す．式(6)，(7)より，状態変数 $\mathbf{U}_{1} ， \mathbf{U}_{2}$ を計算する.

\section{2 境界追跡メッシュの節点座標に関する感度}

本節では, 境界追跡メッシュのレベルセット境界上の節点座標に関して, 目的関数と制約関数の感度を導出す る. $\mathbf{u}_{1}$ は境界追跡メッシュを用いて近似的に計算されるので, 目的関数 $f_{0}(\phi)$ も境界追跡メッシュを用いて近似 的に計算される. 近似的に計算される $f_{0}(\phi)$ を $\tilde{f}_{0}$ と表すと, 式(2)より以下の式が得られる.

$$
\tilde{f}_{0}=-\mathbf{U}_{1}^{\top} \mathbf{T}_{2}
$$


さらに, 式(6)と(9)より, 以下の式が得られる.

$$
\tilde{f}_{0}=-\mathbf{U}_{1}^{\top} \mathbf{T}_{2}+\mathbf{W}^{\top}\left\{\mathbf{T}_{1}-\mathbf{K U}_{1}\right\}
$$

ここで, W は随伴変数べクトルである.

レベルセット境界上の節点座標が変動したときの $\tilde{f}_{0}$ の変動を $\delta \tilde{f}_{0}$ と表すと, 式 $(10)$ より以下の式が得られる.

$$
\delta \tilde{f}_{0}=-\mathbf{U}_{1}^{\top} \delta \mathbf{T}_{2}+\mathbf{W}^{\top}\left\{\delta \mathbf{T}_{1}-\delta \mathbf{K} \mathbf{U}_{1}\right\}-\delta \mathbf{U}_{1}^{\top}\left\{\mathbf{T}_{2}+\mathbf{K}^{\top} \mathbf{W}\right\},
$$

ここで, $\delta \mathbf{T}_{1}, \delta \mathbf{T}_{2}, \delta \mathbf{K}, \delta \mathbf{U}_{1}$ は, それぞれ $\mathbf{T}_{1}, \mathbf{T}_{2}, \mathbf{K}, \mathbf{U}_{1}$ の変動である. 感度の導出を簡単にするために, レ ベルセット境界は $\partial D_{\text {in }}$ と $\partial D_{\text {out }}$ に接触しないものとする．この仮定により $\delta \mathbf{T}_{1}$ と $\delta \mathbf{T}_{2}$ は消去されるので, 以下 の式が得られる.

$$
\delta \tilde{f}_{0}=-\mathbf{W}^{\top} \delta \mathbf{K U}_{1}-\delta \mathbf{U}_{1}^{\top}\left\{\mathbf{T}_{2}+\mathbf{K}^{\top} \mathbf{W}\right\}
$$

$\mathbf{W}=-\mathbf{U}_{2}$ を代入することにより，上式右辺第二項は消去されるので，以下の式が得られる．

$$
\delta \tilde{f}_{0}=\mathbf{U}_{2}^{\top} \delta \mathbf{K} \mathbf{U}_{1}
$$

以上より，レベルセット境界上の節点座標感度は以下のように導出される.

$$
\frac{\partial \tilde{f}_{0}}{\partial X}=\mathbf{U}_{2}^{\top} \frac{\partial \mathbf{K}}{\partial X} \mathbf{U}_{1}, \quad \frac{\partial \tilde{f}_{0}}{\partial Y}=\mathbf{U}_{2}^{\top} \frac{\partial \mathbf{K}}{\partial Y} \mathbf{U}_{1}
$$

ここで, $X$ と $Y$ は, それぞれレベルセット境界上の節点の $x, y$ 座標である.

次に, 制約関数の感度について考える. 近似的に計算される $f_{1}(\phi), f_{2}(\phi), f_{3}(\phi)$ を, それぞれ $\tilde{f}_{1}, \tilde{f}_{2}, \tilde{f}_{3}$ と表 すと，これらは離散系において以下のように計算される.

$$
\begin{aligned}
& \tilde{f}_{1}=\bigcup_{e=1}^{n_{\Omega}} \int_{V^{\mathbf{e}}} \mathrm{d} v \\
& \tilde{f}_{2}=\mathbf{U}_{1}^{\top} \mathbf{T}_{1} \\
& \tilde{f}_{3}=\mathbf{U}_{2}^{\top} \mathbf{T}_{2}
\end{aligned}
$$

$\tilde{f}_{1}$ の感度は以下の様に導出される.

$$
\frac{\partial \tilde{f}_{1}}{\partial X}=\frac{\mathrm{d}}{\mathrm{d} X}\left\{\bigcup_{e=1}^{n_{\Omega}} \int_{V^{\mathrm{e}}} \mathrm{d} v\right\}, \quad \frac{\partial \tilde{f}_{1}}{\partial Y}=\frac{\mathrm{d}}{\mathrm{d} Y}\left\{\bigcup_{e=1}^{n_{\Omega}} \int_{V^{\mathrm{e}}} \mathrm{d} v\right\}
$$

$\tilde{f}_{2}$ と $\tilde{f}_{3}$ の感度は, $\tilde{f}_{0}$ と同様に, 以下の様に導出される.

$$
\begin{array}{ll}
\frac{\partial \tilde{f}_{2}}{\partial X}=-\mathbf{U}_{1}^{\top} \frac{\partial \mathbf{K}}{\partial X} \mathbf{U}_{1}, & \frac{\partial \tilde{f}_{2}}{\partial Y}=-\mathbf{U}_{1}^{\top} \frac{\partial \mathbf{K}}{\partial Y} \mathbf{U}_{1} \\
\frac{\partial \tilde{f}_{3}}{\partial X}=-\mathbf{U}_{2}^{\top} \frac{\partial \mathbf{K}}{\partial X} \mathbf{U}_{2}, & \frac{\partial \tilde{f}_{3}}{\partial Y}=-\mathbf{U}_{2}^{\top} \frac{\partial \mathbf{K}}{\partial Y} \mathbf{U}_{2}
\end{array}
$$

\section{3 オイラーメッシュの節点レベルセット関数に関する感度}

前節では，境界追跡メッシュのレベルセット境界上において，節点座標に関する目的関数と制約関数の感度を

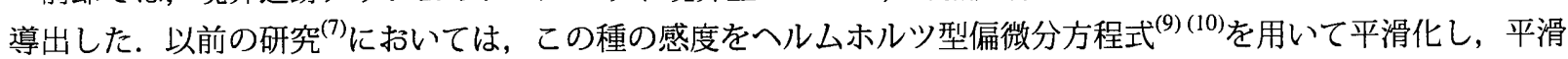
化された感度に基づいてレベルセット方程式の法線方向速度を求め，オイラーメッシュ上でレベルセット方程式 を解くことによって, 反復的にレベルセット関数を更新した. 一方, 本研究においては, 非線形計画法を用いて レベルセット関数を更新する. このため, 本節では, オイラーメッシュの各節点において, レベルセット関数に 関する感度を導出する.

まず，オイラーメッシュと境界追跡メッシュの関係について説明する. オイラーメッシュは, 設計領域を三角 形一次要素を用いて離散化することによって得られ，レベルセット関数は三角形一次要素の各節点において保持 される. そして, 各節点において保持されるレベルセット関数值によって, 物体領域の形状と形態が与えられる. このとき, 対応する境界追跡メッシュは文献 ${ }^{(6)}$ に示す方法により生成される. 
境界追跡メッシュのレベルセット境界上に扔ける, 節点座標に関する感度は前節で求められた. よって, オイ ラーメッシュの各節点のレベルセット関数に関して, 境界追跡メッシュのレベルセット境界上の節点座標の感度 が導出できれば, オイラーメッシュの各節点のレベルセット関数に関する目的関数と制約関数の感度を導出でき る. よって，レベルセット境界上の節点を内包するオイラーメッシュの三角形要素に着目する. その三角形要素 の第一節点, 第二節点, 第三節点における座標を, それぞれ $\left(x_{1}, y_{1}\right),\left(x_{2}, y_{2}\right),\left(x_{3}, y_{3}\right)$ と表記し, レベルセット関 数を $\phi_{1}, \phi_{2}, \phi_{3}$ と表記する. このとき, レベルセット境界上の節点は $\phi=0$ を表す線分上に位置するため, 節点 座標 $(X, Y)$ は以下の式より求められる.

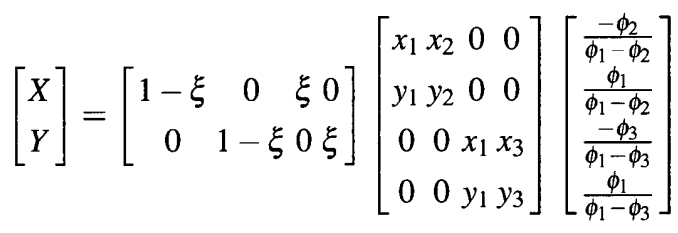

ここで, $\xi$ は線分上の局所座標である. $\xi$ を計算するために, 文献 ${ }^{(6)} て ゙$ 提案している, レベルセット境界上の最近 傍点探索アルゴリズムを用いる. 上式より， $\phi_{1}, \phi_{2}, \phi_{3}$ に関する $X$ と $Y$ の感度は以下の様に導出される.

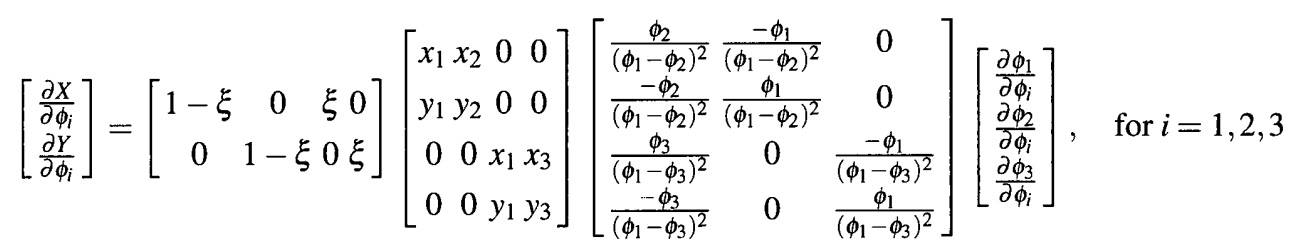

すべてのレベルセット境界上の節点に対して，オイラーメッシュの各節点におけるレベルセット関数に関する 節点座標の感度を, 式 (22) を用いて計算する. オイラーメッシュの各節点におけるレベルセット関数に関する目 的関数・制約関数の感度は, チェインルールを用いて以下の様に導出できる.

$$
\frac{\partial f_{i}}{\partial \phi}=\frac{\partial f_{i}}{\partial X} \cdot \frac{\partial X}{\partial \phi}+\frac{\partial f_{i}}{\partial Y} \cdot \frac{\partial Y}{\partial \phi}, \quad \text { for } i=0,1,2,3
$$

よって, 式 (14)，(18), (19), (20)，(22)を式(23)に代入することにより, オイラーメッシュの各節点におけるレ ベルセット関数に関する, 目的関数と制約関数の感度が最終的に得られる.

\section{4 レベルセット関数更新法}

本節では, 前節で導出された感度と非線形計画法を用いてレベルセット関数を更新する方法について説明する. 本研究では, 文献 ${ }^{(9)}(10)$ で提案される設計変数フィルタを利用する. すなわち, 連続系において以下のようにレべ ルセット関数 $\phi$ を支配する設計変数 $\psi$ を設計領域に導入する.

$$
-R^{2} \nabla^{2} \phi+\phi=\psi \text { in } D
$$

ここで, $R$ はスケールパラメータである. また， $\psi$ の上限扔よび下限を 1 と-1 に設定する. 与えられた $\psi$ に対し

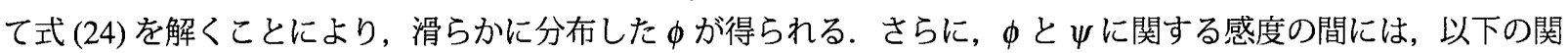
係が成り立つ.

$$
\frac{\partial f_{i}}{\partial \psi}=\frac{\partial f_{i}}{\partial \phi} \cdot \frac{\partial \phi}{\partial \psi} \quad \text { in } D, \quad \text { for } i=0,1,2,3
$$

$\frac{\partial \phi}{\partial \psi}$ は $\left(-R^{2} \nabla^{2}+1\right)$ の逆演算子に対応しているので, 式 (24) と同種のフィルタが, $\phi に$ 関する感度, すなわち $\frac{\partial f_{i}}{\partial \phi}$ に作用する. このフィルタリングにより， $\psi$ に関する感度, すなわち $\frac{\partial f_{i}}{\partial \psi}$ が得られる.

上記の議論より, 設計変数の更新方法は以下の様になる.

(i) 三角形一次要素からなるオイラーメッシュを用意し, オイラーメッシュの各節点において, 設計変数 $\psi$ の初 期值を与える.

(ii) 式 (24) を解くことにより, オイラーメッシュの各節点におけるレベルセット関数 $\phi$ を計算する.

(iii）境界追跡メッシュを生成する.

(iv) 境界追跡メッシュを用いて, 目的関数 $\tilde{f}_{0}$ と制約関数 $\tilde{f}_{1}, \tilde{f}_{2}, \tilde{f}_{3}$ を計算する. 


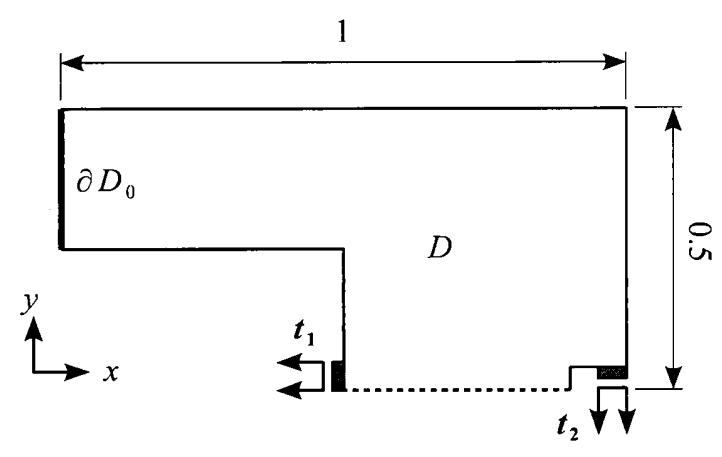

Fig. 1 Design domain and boundary conditions of the numerical example.

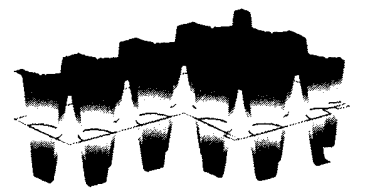

Initial structure

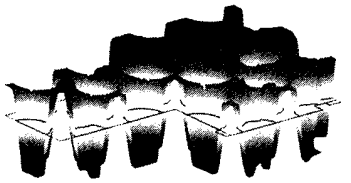

Iteration 51

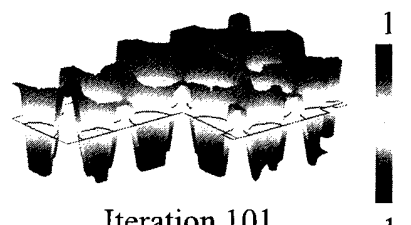

Iteration 101

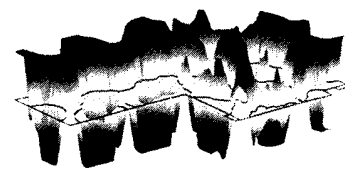

Iteration 201

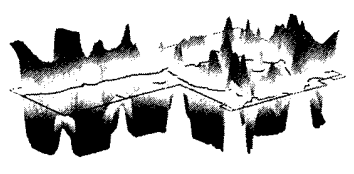

Iteration 401

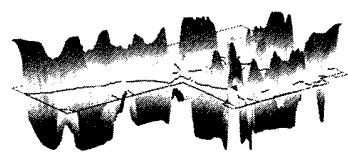

Optimized structure

Fig. 2 Design variables of initial, intermediate, and optimized structures.

(v) 目的関数が収束すれば最適化を終了する.

(vi) $\phi$ に関する感度を計算する.

(vii) 式 (25) に基づき， $\psi$ に関する感度を計算する.

(viii) SLP を用いて設計変数 $\psi$ を更新し，(ii)に戻る.

\section{4. 数 值 例}

本章では，数值例を用いて提案法の有用性を検証する．数值例の設計領域と境界条件を図 1 に示す．この図に 打いて， $\partial D_{0}$ は完全に変位拘束する境界であり，底辺の点線部は対称境界条件が与えられる境界である．また，入 力荷重 $\mathbf{t}_{1}$ と出力荷重 $\mathbf{t}_{2}$ は, それぞれ $(0.01,0)$ と $(-0.01,0)$ に設定され, 設計領域は最大要素長 0.005 で分割され る. 構造材料のヤング率とポアソン比は, それぞれ 1 と 0.3 とする. 式 (8)におけるパラメータ $\kappa$ と, 式 (24)にお けるパラメータRは，それぞれ $1 \times 10^{-6}$ と 0.025 に設定する. $f_{1 \max }, f_{2 \max }, f_{3 \max }$ は, それぞれ $0.12,2.5 \times 10^{-5}$, $1.5 \times 10^{-5}$ に設定する. SLP のムーブリミットは 0.01 に設定する. また, 初期構造においては体積制約条件を大 幅に違反するため, 体積制約条件の上限值 $f_{1 \max }$ は 400 イタレーションをかけて漸減させる.

設計変数 $\psi$ の初期值を，図 2 左上に示すように与えた場合，中間構造，最適構造の設計変数は図 2 に示すよう になる.このとき，対応する物体領域は，図 3 に示すように得られる. 図 4 に最適化の履歴を示す．このグラフ より, 最適化過程に扔て目的関数と制約関数の振動が見られるものの, 最終的には制約条件を満たしつつ, 目 的関数が最小化されているのが分かる. さらに, 図 3 右下に示す最適構造は, 文献 ${ }^{(7)}$ に示すコンプライアントグ リッパーによく似ており, 提案法により, 妥当なコンプライアントメカニズムが得られたと考えられる. 一方で は, 本研究では非線形計画法についての最初の実装として単純なSLP を使用しており, 今後は, 図 4 に示すよう な探索過程の特質などについての検討を重ねて, より構造最適化問題の性質に適した非線形計画法を構成して組 み合わせていくことが課題であると考えている. 


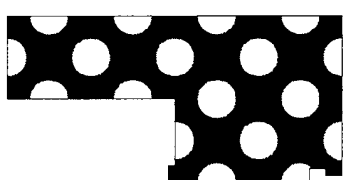

Initial structure

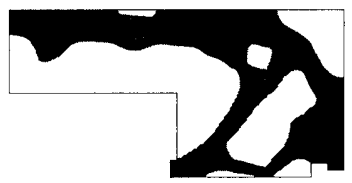

Iteration 201

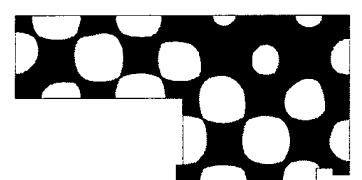

Iteration 51

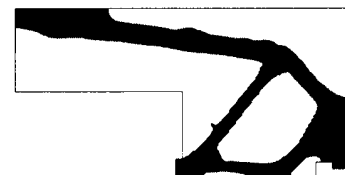

Iteration 401

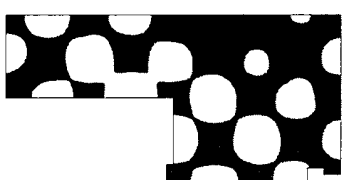

Iteration 101

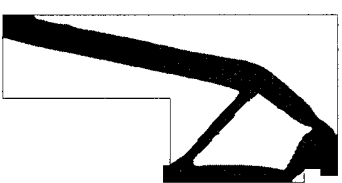

Optimized structure

Fig. 3 Material domains of initial, intermediate, and optimized structures.

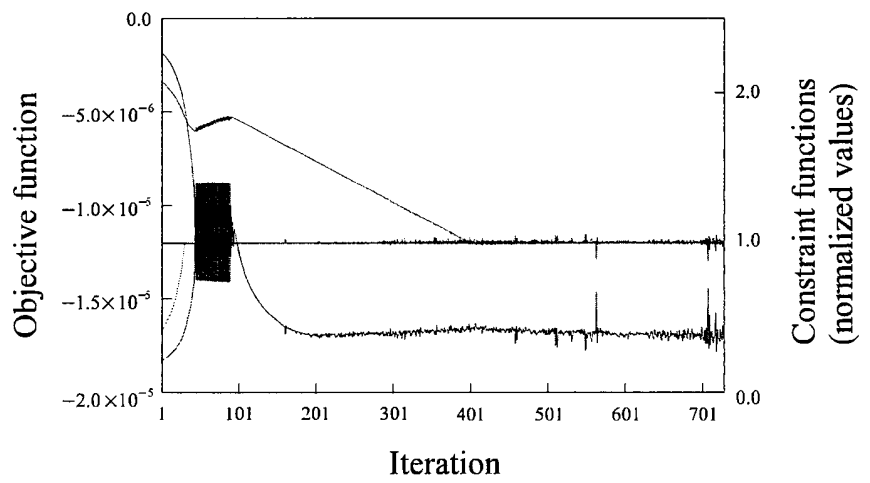

Fig. 4 Optimization history of the objective function $\tilde{f}_{0}$ (blue) and the constraint functions $\tilde{f}_{1}$ (red), $\tilde{f}_{2}$ (green), and $\tilde{f}_{3}$ (orange).

\section{5. 結 論}

本研究では, レベルセット関数の更新を非線形計画法を用いて行う, 新しい境界追跡型レベルセットトポロジー 最適化法を提案した．境界追跡型レベルセットトポロジー最適化においてはグレースケール要素は生成されず，非 線形計画法による設計変数の更新はトポロジー最適化において一般的であるので, 提案法は, 標準的な設計変数更 新の枠組みに基づく, グレースケールフリーのトポロジー最適化法と言える. 非線形計画法の研究分野では, 最 適化問題の性質に合わせて様々な方法が開発されているため，構造最適設計の対象に合わせて好適な非線形計画 法を選択し提案法と組み合わせることにより，効率的な構造最適化の実現が期待できる. 本研究では，その最初 の段階として, SLPを用いてコンプライアントメカニズムの最適設計法を実装し, 妥当な最適構造が得られるこ とを確認した.

\section{文献}

(1) Bendsøe, M. P. and Kikuchi, N., "Generating optimal topologies in structural design using a homogenization method", Computer Methods in Applied Mechanics and Engineering, Vol.71, No.2, (1988), pp.197-224.

(2) Bendsøe, M. P. and Sigmund, O., "Topology optimization theory, methods and applications", 2nd edition, Springer, Berlin, (2003).

(3) Osher, S. and Sethian, J. A., "Fronts propagating with curvature-dependent speed: Algorithms based on Hamilton-Jacobi formulations", Journal of Computational Physics, Vol.78, No.1, (1988), pp.12-49.

(4) Wang, M. Y., Wang, X., and Guo, D., "A level set method for structural topology optimization", Computer Methods in Applied Mechanics and Engineering, Vol.192, No.1-2, (2003), pp.227-246. 
(5) Allaire, G., Jouve, F., and Toader, A. M., "Structural optimization using sensitivity analysis and a level-set method", Journal of Computational Physics, Vol.194, No.1, (2004), pp.363-393.

(6) Yamasaki, S., Nomura, T., Kawamoto, A., Sato, K., and Nishiwaki, S., "A level set-based topology optimization method targeting metallic waveguide design problems", International Journal for Numerical Methods in Engineering, Vol.87, No.9, (2011), pp.844-868.

(7) Yamasaki, S., Kawamoto, A., and Nomura, T., "Compliant mechanism design based on the level set and arbitrary Lagrangian Eulerian methods", Structural and Multidisciplinary Optimization, Vol.46, No.3, (2012), pp.343-354.

(8) Osher, S. and Fedkiw, R., "Level set methods and dynamic implicit surfaces", Springer, New York, (2003).

(9) Lazarov, B. S. and Sigmund, O., "Filters in topology optimization based on Helmholtz-type differential equations", International Journal for Numerical Methods in Engineering, Vol.86, No.6, (2011), pp.765-781.

(10) Kawamoto, A., Matsumori, T., Yamasaki, S., Nomura, T., Kondoh, T., and Nishiwaki, S., "Heaviside projection based topology optimization by a PDE-filtered scalar function", Structural and Multidisciplinary Optimization, Vol.44, No.1, (2011), pp.19-24. 